\title{
$10 \mathrm{MeV}$ proton irradiation effects on $\mathrm{GaInP} / \mathrm{GaAs} / \mathrm{Ge}$ concentrator solar cells and their component subcells
}

\author{
M. Ochoa ${ }^{1}$, E. Yaccuzzi ${ }^{2,3}$, P. Espinet-González ${ }^{1}$, M. Barrera ${ }^{2,3}$, E. Barrigón ${ }^{1}$, M. L. \\ Ibarra $^{2,4}$, Yedileth Contreras ${ }^{1}$, J. García ${ }^{2,3}$, E. López ${ }^{1}$, M. Alurralde², C. Algora ${ }^{1}$, E. \\ Godfrin $^{2}$, I. Rey-Stolle ${ }^{1}$, J. Plá2,3. \\ ${ }^{1}$ Instituto de Energía Solar - Universidad Politécnica de Madrid \\ Av. Complutense 30; 28040 Madrid -Spain \\ ${ }^{2}$ Departamento Energía Solar - Gerencia Investigación y Aplicaciones - CNEA, \\ ${ }^{3}$ Consejo Nacional de Investigaciones Científicas y Técnicas (CONICET) \\ Av. General Paz 1499 - (1650) San Martín - Argentina. \\ ${ }^{4}$ Universidad Nacional de General San Martin, Martín de Irigoyen 3100 \\ (1650). San Martín - Argentina.
}

\begin{abstract}
In this paper, the experimental results of a $10 \mathrm{MeV}$ proton irradiation on concentrator GaInP/GaAs/Ge lattice-matched triple-junction solar cells and their corresponding subcells are examined. Electro-optical characterization such as external quantum efficiency, light and dark I-V measurements, is performed together with theoretical device modeling in order to guide the analysis of the degradation behavior. The GaInP (on $\mathrm{Ge}$ ) and Ge cell showed a power loss between beginning of life and end of life of about $4 \%$ while the $\mathrm{GaInP} / \mathrm{GaAs} / \mathrm{Ge}$ and GaAs solar cells exhibited the highest damage measured of $12 \%$ and $10 \%$, respectively for an irradiation fluence equivalent to an 8years satellite mission in Low Earth Orbit. The results from single-junction solar cells correlate well with those of triple-junction solar cells. The performance of concentrator solar cells structures is similar to that of traditional space-targeted designs reported in literature suggesting that no special changes may be required to use triple junction concentrator solar cells in space.
\end{abstract}

Keywords: multijunction solar cell, irradiation, protons, TCAD, defects. 


\section{Introduction}

Because of the radiation belts surrounding our planet, satellites in Low Earth Orbits (LEO) operate in a harsh radiation environment. Taking into account the relative motion between the satellite and the bombarding particles, we can consider that proton and electron irradiation inside the inner Van Allen belt have an isotropic incidence. Most part of the damage produced is due to protons with energies ranging from a few $\mathrm{keV}$ to hundreds of $\mathrm{MeV}$. Moreover, the satellite is unprotected from cosmic radiation hitting with several kinds of energetic particles. Accordingly, among the key goals of space power engineering are to understand and develop photovoltaic devices that can perform well in this severe environment.

In the past decade, the lattice-matched GaInP/GaAs/Ge triple-junction solar cell (3JSC) has been chosen for space power generation in spacecrafts and satellites mainly as a result of its high efficiency ( $\sim 30 \%$ at AM0), relatively high power-to-mass ratio and good radiation hardness [1-3]. Other existing multijunction solar cell architectures capable of achieving higher efficiencies than the conventional 3J -namely, inverted metamorphic (IMM) solar cells, solar cells including dilute nitride subcells, multijunction devices fabricated through wafer bonding, among others- have not yet fully demonstrated a radiation hardness comparable to the 3JSC case (see for instance Ref: [2]).

Despite the good properties of the GaInP/GaAs/Ge 3JSC at beginning of life (BOL), its electrical performance gets degraded when exposed to charged particles in space such as protons and electrons. Obviously, such radiation damage has a deleterious impact on the electrical performance of the cells (mainly via the degradation of their minority carrier properties [4]) and hence the analysis of solar cell performance emulating the conditions found in real space missions is a must in order to envisage the optimum configuration of the devices and predict their operation in space.

Although extensive literature exists about radiation damage of 3JSCs [1,5-7], the radiation degradation analysis of these cells remains a topic of great scientific interest and debate, as a result of the high complexity of the multijunction structure. Besides, most of the works related to proton damage in multijunction solar cells analyze separately either single junction cells or triple-junction solar cells [8,9]. The analysis of each subcell inside a triple-junction has also been studied indirectly by using different irradiation particle energies to control the depth and thus the subcell to be damaged $[9,10]$ and by using electroluminescence characterization techniques capable of reconstructing the electrical characteristics of each subcell [11,12]. Even though this indirect technique gives excellent results, it does not provide a direct access to the radiation damage in each subcell. Another motivation to increase the number of degradation studies in conventional 3JSCs is that such structure is the baseline of the socalled 4-junction lattice matched multijunction solar cell which inserts a $1 \mathrm{eV}$ dilutenitride cell between the GaAs and Ge subcells [13,14].

In this work we expand the experimental data available to understand the degradation in space of GaInP/GaAs/Ge triple junction solar cells and, in particular we do so by analyzing the radiation resistance of devices whose semiconductor structure has been designed to operate under concentrated light. Space applications of this type of devices 
would also range from near sun missions [15] to alternative space solar panel designs where concentrators are used to reduce the total weight of the panels and increase their efficiency [16]. It should be stressed that devices tested in this work were designed to operate under concentration at about 1000 suns, and this is probably beyond the actual spacecraft tracking accuracy for space concentrator systems. This fact would imply that larger devices should be used for potentially practical applications. Anyway, it is expected that results obtained here will at least hold, given the influence of perimeter recombination in our tiny devices could be considered as not the optimum case for current practical applications.

In this study, we combine degradation experiments of concentrator triple-junction solar cells $(\mathrm{GaInP} / \mathrm{GaAs} / \mathrm{Ge})$ together with their corresponding component subcells in the same experiment and report on the effects of $10 \mathrm{MeV}$ proton irradiation on these cells. The solar cells have been experimentally characterized in situ -i.e. inside the irradiation chamber- by dark and light I-V measurements and ex-situ by deep level transient spectroscopy, and quantum efficiency. Technology Computer Aided Design (TCAD) from Silvaco tools has been used to simulate the solar cells and analyze the experimental findings.

\section{Experimental and modeling}

\subsection{Experimental design and setup}

$10 \mathrm{MeV}$ proton energy is the standard energy used to simulate a space irradiation. The selected fluence represents the fluence received during a space mission in a LEO during 8 years and it was determined using the method previously developed at DES [17]. This method considers the equivalence between space proton spectrum and the $10 \mathrm{MeV}$ monoenergetic proton fluence based on the primary knock-on atoms (PKA) obtained using the TRIM (transport of ions in matter) software [18] for a simplified semiconductor structure representative of each sample. The details for the application of this method are published elsewhere $[17,21]$. The spatial damage was simulated using a total spatial dose of $1.23 \times 10^{12}$ proton $\cdot \mathrm{cm}^{-2}$ calculated for III-V devices using the SPENVIS facility (see ref. [8]). The resulting fluence calculations for all devices were used to design the experiment. Accordingly, to emulate the radiation damage suffered in orbit, III-V solar cells were irradiated by a $10 \mathrm{MeV}$ proton beam produced by the tandem Van de Graaff accelerator of CNEA (Tandar). All experiments were performed under high vacuum using a specially developed chamber installed in one of the experimental lines of the accelerator (for details see also [17-21]). In order to spread the beam, a $10 \mu \mathrm{m}$-thick aluminum foil was installed intercepting the beam path about $6 \mathrm{~m}$ before the chamber. The resulting beam intensity uniformity at the target position was determined prior to the experiment by using an array of 9-Faraday cups (FC) installed a few centimeters from the sample holder. The beam current in each FC was measured using a Keithley 6514 electrometer. The overall beam uniformity was better than $5 \%$ over the whole target area (diameter $\sim 9 \mathrm{~cm}$ ).

During the experiments the samples were positioned in place of the central FC (FC1). Fluence integration and corrections were applied in each case using a calibration factor between a reference FC and FC1 obtained in the previous beam distribution measurement. To observe the degradation of the devices during irradiation, the beam 
was interrupted at four different stages for each solar cell, allowing the in-situ measurement of dark and light I-V curves to take place.

The samples were mounted on a rotatable sample holder able to move without breaking the vacuum to irradiate all of them (i.e. they were sequentially moved to the position of FC1 where they were irradiated one by one). In order to reduce the radiologic activation of the copper holders (see next section), they were shielded by aluminum masks (individual collimators), and thick enough to stop the beam, but featuring appropriate holes just in front of the solar cells for the irradiation. All cells received four accumulated fluences reaching a final total fluence of about $5 \cdot 10^{11} \mathrm{p} / \mathrm{cm}^{2}$.

\subsection{Device fabrication}

For this study we grew and manufactured lattice-matched GaInP/GaAs/Ge 3JSCs as well as component cells for each subcell type, namely, single junction GaAs and Ge solar cells and GaInP/Ge solar cells with active Ge subcells cells (see Table 1). The layer design (in particular, the tunnel junctions and top cell emitter) was adapted to concentrator operation. The active germanium subcell was formed by phosphorous diffusion from a GaInP nucleation layer. For further details on the growth see Refs $[22,23]$

Solar cell epiwafers were processed into small area solar cell devices (see Table 1) following a procedure very similar to that described in [3]. Photolithography was employed to define the front grid, with inverted square symmetry and a shadowing factor of around $4 \%$. The front $(\mathrm{AuGe} / \mathrm{Ni} / \mathrm{Au})$ and back $(\mathrm{Au})$ metal contacts were deposited by thermal evaporation. The wet mesa etching process applied to isolate the devices consisted of an optimized sequence of etching steps using acid and basic solutions. No anti-reflection coating (ARC) was deposited onto the samples. Finally, solar cells were individually encapsulated by soldering each of them with $\mathrm{Sn} / \mathrm{Ag}$ or indium paste to a copper plate (which acted both as the rear contact and the heat sink for the device). The front contact was made using $\mathrm{Al}$ wire bonding to a PCB.

\subsection{In situ and ex situ device characterization}

The cells were characterized ex situ before and after irradiation by quantum efficiency measurements, deep level transient spectroscopy and light I-V measurements. External quantum efficiency (EQE) has been measured with a setup using a Xe-lamp as white light source which goes through a Horiba TRIAX 180 monochromator and an external filter wheel. The light is chopped and a monitor cell is used to compensate for any intensity fluctuations coming from the Xe-lamp. Light I-V measurements were performed in situ before and after each proton fluence using a Sciencetech solar simulator with AM0 filter coupled to the irradiation chamber through a borosilicate window and a source measure unit (SMU) Keithley 2602A with four-wire configuration to avoid cable losses. In addition, ex situ light I-V measurements were carried out under standard test conditions at BOL and end of life (EOL) by using a TS-Space Close Match solar simulator at $T=28^{\circ} \mathrm{C}$ with $1.367 \mathrm{~kW} / \mathrm{m}^{2}$ (equivalent to AM0 spectrum). The irradiance was set using AM0 calibrated GaInP and GaAs isotype cells to adjust the spectral intervals [300-700]nm and [700-900]nm, respectively. Finally, an AM0 
calibrated GaInP/GaAs/Ge triple junction cell was used as a reference for the calibration.

\subsection{TCAD modeling}

Solar cells were also modeled with a 2-D physically-based numerical modeling tool Atlas from Silvaco [24]. This type of modeling solves numerically the fundamental semiconductor equations derived from Maxwell's laws, namely the Poisson equation, the two steady-state continuity equations and the transport drift-diffusion equations under specified bias conditions to compute typical multijunction solar cells characterization curves. Thermionic and thermionic field emission boundary conditions are used to model the non-linear transport at heterojunctions [25]. The transfer matrix method was used to calculate the photo generation rate through the structure. This method accurately takes into account constructive and/or destructive interferences at the interfaces of the solar cell [26]. Radiative and non-radiative recombination mechanisms such as Shockley-Read-Hall (S-R-H), and Auger have been taken into account. In addition, perimeter recombination is considered (see details in [27]) only in our GaAs solar cells because it has been shown that bulk recombination dominates over perimeter at any voltages in our GaInP and Ge solar cells [27,28].

\subsection{Displacement damage dose analysis}

The proton irradiation fluence was converted to the displacement damage dose $\left(D_{d}\right)$ in order to characterize the radiation response of the solar cells $[29,30]$. Since proton irradiation with energy $>0.1 \mathrm{MeV}$ was performed, it is reasonable to calculate the $D_{d}$ as the product of the non-ionization energy loss (NIEL) and the particle fluence [30]. In this case, there is usually a linear dependence between the damage coefficients and the NIEL such as the degradation curve may be explained by a single characteristic curve (i.e. $\mathrm{P}_{\max } \mathrm{vs} D_{d}$ ). Thus, the degradation damage is given by the following semi-empirical expression (see for instance [30]):

$P / P_{0}=1-C \log (1+D d / D x)$

where $D_{d}$ is the displacement damage dose, $P$ and $P_{0}$ can be applied to any photovoltaic parameter (i.e. $\mathrm{J}_{\mathrm{sc}}, \mathrm{V}_{\mathrm{Oc}}, \mathrm{FF}$ and $\mathrm{P}_{\max }$ ) at a dose $D_{d}$ and before irradiation respectively, and $C$ and $D_{x}$ are the fitting parameters. To define a criterion of observable degradation, a value of 0.98 for $\mathrm{P} / \mathrm{P}_{0}$ was chosen as a limit taking into account the estimated experimental error. For the calculation of $D_{d}$, the GaAs NIEL $\left(6.588 \cdot 10-3 \mathrm{MeV} \cdot \mathrm{cm}^{2} / \mathrm{g}\right.$ for $10 \mathrm{MeV}$ protons [29]) was used for any material namely, GaInP, GaAs and Ge. This is mainly because of two reasons: 1) for the proton energy used, the NIEL does not vary significantly for the three materials used in this study [31] and 2) for the 3J solar cell; the observed degradation is dominated by the response of the GaAs subcell.

\section{Results and discussion}

\subsection{Radiation damage on component cells}

Fig. 1 shows the trend degradation of short circuit current density $\left(\mathrm{J}_{\mathrm{sc}}\right)$, open circuit voltage $\left(\mathrm{V}_{\mathrm{oc}}\right)$, fill factor $(\mathrm{FF})$ and maximum power $\left(\mathrm{P}_{\max }\right)$ observed in situ in Ge and GaAs single junction and GaInP/Ge double junction solar cells at different $D_{d}$. In the case of the GaAs cell, it exhibits the highest damage measured. The $P_{\max }$ starts to 
decrease for a $D_{d}>3 \cdot 10^{8} \mathrm{MeV} / \mathrm{g}$ showing a power loss of $10 \%$ for the final $D_{d}$ as illustrated in Fig. 1(d). The main contribution to $\mathrm{P}_{\max }$ loss comes from the reduction of $\mathrm{V}_{\text {oc }}(5.7 \%)$ while the drop in photocurrent is lower (3\%).

Regarding the Ge solar cell its $\mathrm{P}_{\max }$ shows signs of slight degradation mainly at final $D_{d}$. A $\mathrm{V}_{\text {oc }}$ loss of about $2 \%$ is observed while the photocurrent and FF drop by $1-2 \%$ and $1 \%$, respectively. This is equivalent to a $\mathrm{P}_{\max }$ loss of about $4 \%$. For the GaInP/Ge cell, $\mathrm{P}_{\max }$ starts to decrease for $D_{d}>4.5 \cdot 10^{8} \mathrm{MeV} / \mathrm{g}$ exhibiting an absolute loss of about $4 \%$ for the final $D_{d}$. The overall loss in this cell is a combination of degradation in $\mathrm{V}_{\text {oc }}$ $(0.8 \%), \mathrm{J}_{\mathrm{sc}}(0.6 \%)$ and FF (1.6\%). All solid lines in Fig. 1 correspond to the data fitting obtained by using Eq. 1 and the resulting fitting parameters are presented in Table 2.

Fig. 2 shows the dark I-V curves at BOL and EOL for the same cells. The Ge recombination currents at BOL and EOL are almost equal having a slight $10 \%$ shift between them which eventually yield to a $\mathrm{V}_{\text {oc }}$ loss of $3 \mathrm{mV}$ being consistent with Fig. 1. Similar results have been found for Ge subcells in a triple-junction solar cell for comparable conditions as the ones used in this study [4,8,12,32]. The dark I-V curves of 2J GaInP/Ge show larger shifting (30\%) to higher recombination currents from BOL to EOL which is equivalent to a $12 \mathrm{mV}$ loss at open circuit conditions also in accordance to Fig. 1 . This loss can be attributable mainly to a degradation of minority carrier properties in GaInP and in some extent to the Ge subcell. In agreement with the light IV curves, the highest damage is confirmed for GaAs solar cells as could be observed in Fig. 1 (a), (b) and (d) and Fig. 2 where the larger differences between the recombination current at BOL and EOL will be discussed later.

In order to investigate where the damage took place inside the solar cell, EQE measurements have been performed before and after the irradiation. In the case of $\mathrm{Ge}$ and $\mathrm{GaInP} / \mathrm{Ge}$ solar cells, no significant degradation is observed in their photocurrent (lower than 2\% and within experimental error), fact that is confirmed with their EQEs (not plotted here). However, the EQE of the GaAs solar cell shows noticeable differences (which correspond to a 3\% current loss) as illustrated in Fig. 3(a) along with the corresponding data fitting from TCAD modeling. The degradation of the EQE starts around $600 \mathrm{~nm}$ up to the cut-off wavelength. At this region, the dominant photo generation rate (PGR) and the final photocurrent is a mixture of emitter+base contributions as can be seen in Fig. 3(b) (the sum of BSF, buffer and substrate photocurrents is too low to be considered). As a result of the PGR calculation, we find that for regions where the emitter is dominant $(400<\lambda<550 \mathrm{~nm})$, there is no degradation of the EQE indicating that most of the damage took place at the base region.

Accordingly, in order to fit the EQE at EOL (blue diamonds of Fig. 3(a)), only changes at the base region were made and an excellent fit could be attained (blue solid line in Fig. 3(a)).

One of the primary consequences of proton irradiation is the physical displacement of atoms that may lead to vacancies, interstitials or even cluster defects all of them creating different energy levels within the gap and thus affecting the electrical performance of the solar cell $[6,33,34,35]$. These defects can act as traps, recombination centers or as compensation (or carrier removal) sites where the free charge introduced by dopants is localized at the defect effectively reducing the free carrier concentration [35]. Carrier 
removal is not the radiation damage mechanism in our GaAs solar cells since electrical $\mathrm{C}-\mathrm{V}$ measurements (not shown here) indicate no significant difference at the base doping level before and after the irradiation $\left(1.2 \cdot 10^{17} \mathrm{~cm}^{-3}\right.$ and $1.3 \cdot 10^{17} \mathrm{~cm}^{-3}$, respectively). Moreover, carrier removal usually occurs for higher fluences than the ones used here $[7,35]$.

On the contrary, the formation of vacancies, interstitials or cluster defects is the most probable cause behind the degradation observed $[6,33,34,35]$. After proton irradiation, the new defects (or native) may change in density and capture cross sections depending on the particle energy and cumulated proton fluence used in the experiments [32]. Therein, we have performed DLTS measurements (not shown here) finding one well defined trap level (hole trap corresponding to a majority carrier trap) located at $0.46 \mathrm{eV}$ from the valence band minima with capture cross section of $4.4 \cdot 10^{-16} \mathrm{~cm}^{2}$ similar to Refs. [36,37]. After irradiation, no significant changes were observed in the properties of these defects and no other levels were found. These measurements confirm that deep levels associated with majority carriers do not significantly contribute to degradation after irradiation as expected [34]. Nevertheless, as suggested by Fig. 3(a), the performance losses in GaAs are related to the alteration of the minority carrier trap density and/or properties after the irradiation. To the best of our knowledge, no values of minority carrier defects after proton irradiation experiments in p-type regions have been reported in the literature. There are some studies where DLTS measurements showed the presence of more than one defect level (majority or minority) in n-type regions of $\mathrm{p}^{+} \mathrm{n}$ type GaAs cells but nothing related to the study of a p-type region which is our case $[33,34,38]$. Given the difficulty to measure minority carrier traps, we have overcome the lack of information about the defects properties through numerical simulations. S-R-H recombination is modeled by including a specific defect density located at the middle of the band gap energy [39]. In most GaAs solar cells, the recombination losses are dominated by S-R-H recombination at the space charge region and the perimeter both at low forward voltages and at the quasi-neutral regions at high forward voltage bias (above $0.9 \mathrm{~V}$ for a $1 \mathrm{~mm}^{2}$ device) [27]. Even though multiple defects and thus energy levels may arise from $10 \mathrm{MeV}$ proton irradiation, it can be possible that one particular defect level dominates over the others [37]. In this case, one single defect level has been able to reproduce the EQE as shown in Fig. 3(a). In order to fit BOL and EOL data, the bulk defect density of electron traps at the base region has been increased about 30 times from $\mathrm{BOL}=5 \cdot 10^{12} \mathrm{~cm}^{-3}$ (resulting in the simulated curve plotted as the black dashed line in Fig. 3(a)) to EOL $=1.5 \cdot 10^{14} \mathrm{~cm}^{-3}$ (solid blue line in Fig. 3(a)). The higher density of traps reduces the diffusion length of carriers affecting the carrier collection from the base layer and thus its contribution to the EQE.

To provide consistency to the EQE data fitting, dark I-V curves have been computed and fitted simultaneously for the GaAs component cell with the same material parameters and models. A good agreement has been achieved at BOL and EOL for dark I-V curves as can be seen in Fig. 4.

In order to fit the EOL I-V curve of Fig. 4, we have fixed the bulk traps estimated from EQE data fitting and vary the properties of the perimeter. Perimeter trap density has been increased one order of magnitude, from a surface defect density of $5 \cdot 10^{12} \mathrm{~cm}^{-2}$ to $5 \cdot 10^{13} \mathrm{~cm}^{-2}$ (perimeter recombination does not impact the EQE response because it is 
measured at short circuit conditions). In such small GaAs solar cells (about $1 \mathrm{~mm}^{2}$ ), perimeter recombination dominates the low voltage behavior (no perimeter passivation is employed) and its properties can be modified by proton irradiation. Anyhow, typical space solar cells have much larger areas (for instance $8 \times 4 \mathrm{~cm}^{2}$ ) and hence lower perimeter to area ratios than the solar cell measured here. At higher voltages the fitting is achieved by the increase of minority bulk trap density (as described above) that also degrades the photocurrent as shown in the EQE data [4]. The slight deviation between the fit and the experimental data in the EOL curve (blue) between 0.9-1.05 V may be attributed to the presence of more than one energy level $[34,38]$.

In summary, the $\mathrm{J}_{\mathrm{sc}}$ for single junction GaAs cells is affected mainly by the reduction in the diffusion length of carriers at the base region due to higher concentration of recombination centers while the $\mathrm{V}_{\text {oc }}$ reduction at EOL is suggested from modelling to be a combination of losses between: a) recombination centers (70\%), and b) perimeter recombination (30\%). On the contrary, the loss in $\mathrm{V}_{\text {oc }}$ attributable to the reduction in $\mathrm{J}_{\mathrm{sc}}$ is negligible (less than $1 \mathrm{mV}$ ) due to the limited fall in $\mathrm{J}_{\mathrm{sc}}(3 \%)$. Finally, it is worthwhile to mention that the GaAs degradation curves of Fig. 1 can be corrected for perimeter recombination in order to compare these results with larger space solar cells. If the degradation curves are corrected (neglecting perimeter recombination), they can still be fitted by the same set of fitting parameters shown in Table 2. This is mainly due to the fact that perimeter losses do not vary significantly between BOL and EOL (5 mV at $\mathrm{V}_{\text {oc }}$ ) and they lie between experimental error and fitting deviation. This fact provides more confidence when comparing the fitting parameters of Table 2 with larger solar cells.

\subsection{Radiation damage on triple-junction solar cells}

In the case of the triple-junction solar cell (Fig. 5), the $P_{\max }$ starts to decrease at very low $D_{d}>7 \cdot 10^{7} \mathrm{MeV} / \mathrm{g}$ reaching about $12 \%$ loss at the final $D_{d}\left(3.15 \cdot 10^{9} \mathrm{MeV} / \mathrm{g}\right)$. This reduction is consistent with the radiation damage found on individual cells as shown above. For comparison with literature, the fitting parameters to Eq. 1 are shown in the inset table of Fig. 5(c).

Fig. 6 shows the EQE of one of the triple junction solar cells before (red lines) and after irradiation (black lines). As shown in this Fig., the GaInP top cell EQE is slightly affected in the base region, which corresponds to a 1.5\% loss between BOL and EOL by integrating the product of the $\operatorname{AMO}(\lambda)$ spectrum and the $\operatorname{EQE}(\lambda)$. On the other hand, the GaAs subcell $J_{\mathrm{sc}}$ drops by 9\% in the wavelength range between 700 - $900 \mathrm{~nm}$ evidencing a lowering of the minority carrier diffusion length in the base region as the GaAs component subcell case (see black and red dashed lines in Fig. 6).

An interesting effect is observed in the Ge bottom cell, whose EQE seems to increase after proton irradiation. This effect suggests a quenching of the photon coupling between the middle and bottom subcells after irradiation [40]. Before irradiation, the measured EQE of the Ge bottom cell is artificially low and shows some extra response from $800 \mathrm{~nm}$ to $900 \mathrm{~nm}$ as a result of photon coupling from the GaAs middle cell [41]. Once irradiated, the radiative recombination of the middle cell is greatly decreased and an artifact-free EQE of the bottom cell is measured. If the measurement artifact of the EQE before irradiation is corrected [42], there is no significant difference between the 
corrected BOL EQE (blue dashed line) and EOL EQE of the Ge subcell ( $\mathrm{J}_{\mathrm{sc}}$ is $0.4 \%$ lower than corrected BOL). The EQE of the Ge subcell at EOL differs in 1.6\% from the component cell case, however, it should be kept in mind that the light is filtered by top and middle cells in the 3JSC case and this difference is small enough compared to the measurements uncertainty.

Fig. 6 contains an additional evidence to further substantiate the conclusion that the EQE of the triple junction solar cell can be understood just by the superposition of the individual behavior observed in irradiated component subcells. This evidence is obtained by plotting the EQE of fresh (red dashed line) and irradiated (black dashed line) single junction GaAs cells in their overlapping spectral range (600 to 880nm). The EQE of both devices (GaAs single junction and GaAs middle subcell in the triple junction) show an excellent agreement disregarding the oscillations that appear in the GaAs middle cell resulting from the optical interference of the GaInP top cell. This backs the idea that the analysis made for the degradation of the GaAs single junction device also applies for the middle subcell in the 3JSC design.

Fig. 7 shows light I-V measurements of a triple junction solar cell device with no ARC before and after the irradiation. As summarized in the inset table, $\mathrm{V}_{\text {oc }}$ losses are about $70 \mathrm{mV}$ after the irradiation which is in agreement with the $\mathrm{V}_{\text {oc }}$ losses from component subcells GaInP and GaAs (12 $\mathrm{mV}$ and $55 \mathrm{mV}$, respectively). Since this is a middle-cell limited device under AM0 spectrum, the photocurrent losses are attributed to the degradation of the EQE GaAs subcell (see Fig. 6).

Finally, as can be noticed in Table 3, the absolute differences in I-V parameters between BOL and EOL conditions confirm a high correlation between the experimental degradation of triple junction solar cells with their related component subcells.

\section{Conclusions}

The effects of $10 \mathrm{MeV}$ proton irradiation in concentrator lattice-matched triple-junction solar cells GaInP/GaAs/Ge and their corresponding component subcells have been studied experimentally and theoretically by means of TCAD modeling. The GaAs solar cell exhibited the highest damage while GaInP/Ge and Ge showed slight signs of degradation at their corresponding final cumulated fluences. The degradation results of the component subcells (individually grown) are consistent with the degradation observed in the triple junction solar cell. The 3JSC losses a 3\% in photocurrent while losses in $\mathrm{V}_{\text {oc }}$ are on the order of $70 \mathrm{mV}$ which corresponds fairly well to the degradation of Ge, GaAs and the GaInP component cells. A single-defect model can reproduce the degradation damage observed on bulk and perimeter of GaAs solar cells for the accumulated fluences used here. However, the presence of multiple defects at different energy levels cannot be neglected. In summary, concentrator solar cell structures show similar results than those of traditional space-targeted designs reported in literature suggesting that no particular changes may be expected if using triple-junction concentrator cells in space.

\section{Acknowledgements}

In Spain, this work was supported by the Ministerio de Economía y Competitividad through the project with reference TEC2012-37286 and by the Comunidad de Madrid 
under the program with reference S2013/MAE-2780. In Argentina, this work was supported by the grant MINCyT-MICINN2012-2013, project ES/11/04, and the grants ANPCyT-PICT2007 No 1143 and CONICET-PIP2009-2011 No 2318. EY, MLI, and JAG have been supported by CONICET doctoral fellowships.

\section{References}

[1] M. A. Stan, D. J. Aiken, P. R. Sharps, N. S. Fatemi, F. A. Spadafora, J. Hills, H. Yoo, and B. Clevenger, "27.5\% efficiency InGaP/InGaAs/Ge advanced triple junction (ATJ) space solar cells for high volume manufacturing”, in Conference Record of the 29th IEEE Photovoltaic Specialists Conference,2002, pp. 816-819.

[2] J. G. J. Adams, V. C. Elarde, G. Hillier, C. Stender, F. Tuminello, A. Wibowo, C. Youtsey, Z. Bittner, S. M. Hubbard, E. B. Clark, M. F. Piszczor, and M. Osowski, "Improved radiation resistance of epitaxial lift-off inverted metamorphic solar cells”, in 2013 IEEE 39th Photovoltaic Specialists Conference (PVSC), 2013, pp. 3229-3232.

[3] M. Imaizumi, T. Takamoto, T. Sumita, T. Ohshima, M. Yamaguchi, S. Matsuda, A. Ohi, and T. Kamiya, "Study of radiation response on single-junction component sub-cells in triple-junction solar cells", 3rd World Conerence on Photovoltaic Energy Conversion, 2003. Proc., vol. 1, 2003.

[4] S. I. Sato, H. Miyamoto, M. Imaizumi, K. Shimazaki, C. Morioka, K. Kawano, and T. Ohshima, "Degradation modeling of InGaP/GaAs/Ge triple-junction solar cells irradiated with various-energy protons”, Sol. Energy Mater. Sol. Cells, vol. 93, no. 6-7, pp. 768-773, 2009.

[5] S. I. Sato, T. Ohshima, and M. Imaizumi, "Modeling of degradation behavior of InGaP/GaAs/Ge triple-junction space solar cell exposed to charged particles”, $J$. Appl. Phys., vol. 105, no. 4, 2009.

[6] S. I. Maximenko , M. P. Lumb , S. R. Messenger , R. Hoheisel , C. Affouda , D. Scheiman , M. Gonzalez , J. Lorentzen , P. P. Jenkins and R. J. Walters, "Degradation modeling of InGaP/GaAs/Ge triple-junction solar cells irradiated by protons", Proc, SPIE 8981, Physics, Simulation, and Photonic Engineering of Photovoltaic Devices III, 2014.

[7] S. I. Maximenko, S. R. Messenger, R. Hoheisel, D. Scheiman, M. Gonzalez, J. Lorentzen, P. P. Jenkins, and R. J. Walters, "Characterization of high fluence irradiations on advanced triple junction solar cells", in Conference Record of the 39th IEEE Photovoltaic Specialists Conference, 2013, pp. 2797-2800.

[8] R. J. Walters, J. H. Warner, G. P. Summers, S. R. Messenger, and J. R. Lorentzen, "Radiation response mechanisms in multijunction III-V space solar cells”, in Conference Record of the 31st IEEE Photovoltaic Specialists Conference, 2005, pp. 542-547.

[9] M. Imaizumi, T. Takamoto, T. Ohshima, M. Yamaguchi, H. Itoh, and S. Matsuda, "Radiaton effects on high-efficiency InGaP/InGaAs/Ge triple-junction solar cells developed for terrestrial use”, in Conference Record of the 29th IEEE Photovoltaic Specialists Conference, 2002, pp. 990-993.

[10] T. Sumita, M. Imaizumi, S. Matsuda, T. Ohshima, A. Ohi, and H. Itoh, "Proton radiation analysis of multi-junction space solar cells”, Nucl. Instruments Methods 
Phys. Res. Sect. B Beam Interact. with Mater. Atoms, vol. 206, pp. 448-451, May 2003.

[11] T. Nakamura, M. Imaizumi, S. Sato, and T. Ohshima, "Change in I-V characteristics of subcells in a multi-junction solar cell due to radiation irradiation", in Conference Record of the 38th IEEE Photovoltaic Specialists Conference, 2012, pp. 2486-2850.

[12] R. Hoheisel, F. Dimroth, A. W. Bett, S. R. Messenger, P. P. Jenkins, and R. J. Walters, "Electroluminescence analysis of irradiated GaInP/GaInAs/Ge space solar cells”, Sol. Energy Mater. Sol. Cells, vol. 108, pp. 235-240, 2013.

[13] T. Thomas, M. Fuhrer, D. A. Alvarez, N. Ekins-Daukes, K. H. Tan, S. Wicaksono, W. K. Loke, S. F. Yoon, and A. Johnson, “GaNAsSb 1-eV solar cells for use in lattice-matched multi-junction architectures”, in Conference record of the 40th IEEE Photovoltaic Specialists Conference, 2014, pp. 05500553.

[14] “http://www.sj-solar.com/about_us/space.php.” .

[15] "Solar Probe Plus: Report of the Science and Technology Definition Team", Report of the American National Aeronautics and Space Administration NASA/TM-2008-214161, July 2008. Available on http://solarprobe.gsfc.nasa.gov/spp_resources.htm

[16] M. J. O’Neill, “1,000 W/kg Solar Concentrator Arrays for Far-Term Space Missions”, in AIP Conference Proceedings, 2004, vol. 699, no. 1, pp. 875-882.

[17] M. Alurralde, "Method using the primary knock-on atom spectrum to characterize electrical degradation of monocrystalline silicon solar cells by space protons”, J. Appl. Phys., vol. 95, no. 7, p. 3391, 2004.

[18] http://www.srim.org/

[19] J. F. Ziegler, http://www.research.ibm.com/ionbeams

[20] M. Alurralde, M. Barrera, C.G. Bolzi, C.J. Bruno, P. Cabot, E. Carella, J. Di Santo, J.C. Durán, J. Fernández Vázquez, A. Filevich, C.D. Franciulli, E.M. Godfrin, V. Goldbeck, A. Iglesias, M.G. Martínez Bogado, E. Mezzabolta, A. Moglioni, C. Nigri, S.L Nigro, F. Palumbo, J. Plá, I. Prario, M.C. Raffo Calderón, S.E. Rodríguez, H. Socolovsky, M.J.L. Tamasi, A. Vertanessian, "Advances in the Development of Photovoltaics for Space Applications in Argentina”, in Proceedings of the 22nd European Photovoltaic Solar Energy Conference and Exhibition, Milan-Italy, 2007, p. 687-691.

[21] A. Filevich, C. J. Bruno, J. F. Vázquez, M. Alurralde, I. Prario, M. J. L. Tamasi, M. G. M. Bogado, J. C. Plá, J. Durán, J. Schuff, A. Burlón, P. Stoliar, D. Minsky, A. J. Kreiner, and R. Mayer, "A Compact Portable Setup for In Situ Solar Cells Degradation Studies”, IEEE Trans. Nucl. Sci., vol. 50, no. 6 I, pp. 2380-2384, 2003.

[22] I. García, I. Rey-Stolle, B. Galiana, and C. Algora, “A 32.6\% efficient latticematched dual-junction solar cell working at 1000 suns”, Appl. Phys. Lett., vol. 94, no. 5, pp. 5-8, 2009.

[23] E. Barrigon, I. Rey-Stolle, B. Galiana, I. Garcia, and C. Algora, “GaInP/GaInAs/Ge triple junction solar cells for ultra high concentration”, 2009 
Spanish Conf. Electron Devices, 2009.

[24] “Silvaco Software. Atlas User’s Manual”, 2015.

[25] K. Yang, J. R. East, and G. I. Haddad, "Numerical modeling of abrupt heterojunctions using a thermionic-field emission boundary condition", Solid. State. Electron., vol. 36, no. 3, pp. 321-330, 1993.

[26] E. Centurioni, “Generalized matrix method for calculation of internal light energy flux in mixed coherent and incoherent multilayers.”, Appl. Opt., vol. 44, no. 35, pp. 7532-7539, 2005.

[27] M. Ochoa, C. Algora, P. Espinet-González, and I. García, “3-D modeling of perimeter recombination in GaAs diodes and its influence on concentrator solar cells”, Sol. Energy Mater. Sol. Cells, vol. 120, pp. 48-58, 2014.

[28] P. Espinet-González, I. Rey-Stolle, M. Ochoa, C. Algora, I. García, and E. Barrigón, "Analysis of perimeter recombination in the subcells of GaInP/GaAs/Ge triple-junction solar cells”, Prog. Photovoltaics Res. Appl., vol. 23, no. 7, pp. 874-882, 2015.

[29] G. P. Summers, R. J. Walters, M. A. Xapsos, E. A. Burke, S. R. Messenger, P. Shapiro, and R. L. Statler, "A new approach to damage prediction for solar cells exposed to different radiations,” in Proceedings of 1994 IEEE 1st World Conference on Photovoltaic Energy Conversion - WCPEC (A Joint Conference of PVSC, PVSEC and PSEC), 1994, vol. 2, pp. 2068-2075.

[30] S. R. Messenger, G. P. Summers, E. A. Burke, R. J. Walters, and M. A. Xapsos, "Modeling solar cell degradation in space: A comparison of the NRL displacement damage dose and the JPL equivalent fluence approaches,” Prog. Photovoltaics Res. Appl., vol. 9, no. 2, pp. 103-121, 2001.

[31] R. J. Walters, G. P. Summers, and S. R. Messenger, "Analysis and modeling of the radiation response of multijunction space solar cells," in Conference Record of the Twenty-Eighth IEEE Photovoltaic Specialists Conference, 2000, pp. 10921097.

[32] T. Ohshima, H. Miyamoto, M. Imaizumi, C. Morioka, S. Kawakita, K. Shimazaki, K. Kibe, K. Kawano, and H. Itoh, “Current Injection Effects on the Electrical Performance of 3J Solar Cells Irradiated with Low and High Energy Protons", in Conference Record of the 4th World Conference on Photovoltaic Energy Conversion, 2006, pp. 1818-1821.

[33] J. H. Warner, C. D. Cress, S. R. Messenger, R. J. Walters, S. A. Ringel, and J. Park, “A Deep Level Transient Spectroscopy Study of Electron and Proton Irradiated p+n GaAs Diodes”, IEEE Trans. Nucl. Sci., vol. 57, no. 4, pp. 282285, 2010.

[34] M. Turowski, T. Bald, A. Raman, A. Fedoseyev, J. H. Warner, C. D. Cress, and R. J. Walters, "Simulating the radiation response of GaAs solar cells using a defect-based TCAD model”, IEEE Trans. Nucl. Sci., vol. 60, no. 4, pp. 24772485, 2013.

[35] S. R. Messenger, R. Hoheisel, J. Lorentzen, D. Scheiman, J. H. Warner, M. Gonzalez, and P. P. Jenkins, "High fluence irradiations on triple junction solar 
cells”, in 2013 IEEE 39th Photovoltaic Specialists Conference (PVSC), 2013, pp. 3121-3127.

[36] D. V. Lang, R. A. Logan, and L. C. Kimerling, "Identification of the defect state associated with a gallium vacancy in GaAs and $\mathrm{Al}_{\mathrm{x}} \mathrm{Ga}_{1-\mathrm{x}} \mathrm{As}$ ”, Phys. Rev. B, vol. 15, no. 10, pp. 4874-4882, 1977.

[37] H.-Z. Zhu, Y. Adachi, and T. Ikoma, "Deep levels in MOCVD GaAs grown under different Ga/As mol fractions”, J. Cryst. Growth, vol. 55, no. 1, pp. 154163, 1981.

[38] J. H. Warner, R. J. Walters, S. R. Messenger, G. P. Summers, S. M. Khanna, D. Estan, L. S. Erhardt, and A. Houdayer, "High-energy proton irradiation effects in GaAs devices”, IEEE Trans. Nucl. Sci., vol. 51, no. 5 III, pp. 2887-2895, 2004.

[39] W. Shockley and W. T. Read, "Statistics of the Recombination of Holes and Electrons”, Physical Review, vol. 87. pp. 835-842, 1952.

[40] C. Baur, M. Hermle, F. Dimroth and A. W. Bett. "Effects of Optical Coupling in III-V Multilayer Systems.” Applied Physics Letters 90 (19): 1-4, 2007.

[41] S. H. Lim, J.-J. Li, E. H. Steenbergen, and Y.-H. Zhang, "Luminescence coupling effects on multijunction solar cell external quantum efficiency measurement", Prog. Photovoltaics Res. Appl., vol. 21, no. 3, pp. 344-350, 2013.

[42] M. A. Steiner, J. F. Geisz, T. E. Moriarty, R. M. France, W. E. McMahon, J. M. Olson, S. R. Kurtz, and D. J. Friedman, "Measuring IV curves and subcell photocurrents in the presence of luminescent coupling”, IEEE J. Photovoltaics, vol. 3, no. 2, pp. 879-887, 2013. 


\begin{tabular}{|c|c|c|c|}
\hline Junctions & $\begin{array}{l}\text { Active } \\
\text { area } \\
\left(\mathrm{cm}^{2}\right)\end{array}$ & \multicolumn{2}{|c|}{$\begin{array}{l}\text { Final fluences } \\
\left(10^{11} \mathbf{p} / \mathbf{c m}^{2}\right)\end{array}$} \\
\hline GaInP/Ge & 0.01 & 3.35 & 3.81 \\
\hline GaAs & 0.01 & 2.93 & 4.99 \\
\hline $\mathrm{Ge}$ & 0.1 & 3.59 & 3.6 \\
\hline GaInP/GaAs/Ge & 0.01 & 3.76 & 4.78 \\
\hline
\end{tabular}

Table 1. Solar cell structures subjected to $10 \mathrm{MeV}$ proton irradiation.

The GaAs solar cell was grown on a highly doped p-type GaAs substrate while the other solar cells were grown on Ge substrates. Two different devices have been irradiated for each solar cell and their corresponding fluences are shown in the last two columns. 


\begin{tabular}{|c|c|c|}
\hline & C & $\mathrm{D}_{\mathrm{x}}(\mathrm{MeV} / \mathrm{g})$ \\
\hline \multicolumn{3}{|c|}{ GaInP/Ge } \\
\hline $\mathbf{J}_{\mathrm{sc}}$ & 0.500 & $4.6 \cdot 10^{10}$ \\
\hline$V_{\text {oc }}$ & 0.011 & $3.7 \cdot 10^{8}$ \\
\hline $\mathbf{P}_{\max }$ & 0.672 & $1.6 \cdot 10^{10}$ \\
\hline \multicolumn{3}{|c|}{ GaAs } \\
\hline $\mathbf{J}_{\mathrm{sc}}$ & 0.642 & $2.6 \cdot 10^{10}$ \\
\hline$V_{\text {oc }}$ & 0.063 & $4.8 \cdot 10^{8}$ \\
\hline $\mathbf{P}_{\max }$ & 0.183 & $1.2 \cdot 10^{9}$ \\
\hline \multicolumn{3}{|c|}{ Ge } \\
\hline $\mathbf{J}_{\mathrm{sc}}$ & 0.031 & $1.2 \cdot 10^{9}$ \\
\hline$V_{\text {oc }}$ & 0.390 & $1.7 \cdot 10^{10}$ \\
\hline $\mathbf{P}_{\max }$ & 0.633 & $1.4 \cdot 10^{10}$ \\
\hline
\end{tabular}

Table 2. Fitting parameters of Eq. 1 to $\mathrm{J}_{\mathrm{sc}}, \mathrm{V}_{\mathrm{oc}}$ and $\mathrm{P}_{\max }$ degradation curves of Fig. 1. 


\begin{tabular}{lllllllll} 
Solar cell & $\begin{array}{l}\boldsymbol{\Delta} \mathbf{V}_{\mathbf{o c}} \\
(\mathbf{m V})\end{array}$ & $\begin{array}{l}\text { Relative } \\
\text { loss }\end{array}$ & $\begin{array}{l}\boldsymbol{\Delta} \mathbf{J}_{\text {sc }} \\
\left(\mathbf{m A} / \mathbf{c m}^{2}\right)\end{array}$ & $\begin{array}{l}\text { Relative } \\
\text { loss }\end{array}$ & $\begin{array}{l}\Delta \mathbf{F F} \\
\mathbf{( \% )}\end{array}$ & $\begin{array}{l}\text { Relative } \\
\text { loss }\end{array}$ & $\begin{array}{l}\Delta \mathbf{P}_{\text {max }} \\
\left(\mathbf{m W} / \mathbf{c m}^{2}\right)\end{array}$ & $\begin{array}{l}\text { Relative } \\
\text { loss }\end{array}$ \\
\hline \hline Ge & 3.8 & $1.6 \%$ & 0.86 & $1.5 \%$ & 0.56 & $0.09 \%$ & 0.32 & $4 \%$ \\
GaAs & 54 & $5.67 \%$ & 0.55 & $2.3 \%$ & -0.07 & $-0.08 \%$ & 1.48 & $7.8 \%$ \\
GaInP/Ge & 11 & $0.75 \%$ & 0.09 & $0.6 \%$ & 0.90 & $1.10 \%$ & 0.42 & $2.4 \%$ \\
GaInP/GaAs/Ge & 69 & $2.88 \%$ & 0.39 & $3.2 \%$ & 0.75 & $0.90 \%$ & 1.69 & $6.8 \%$ \\
\hline \hline
\end{tabular}

Table 3. Absolute differences and relative loss in I-V parameters between BOL and EOL conditions for the solar cells analyzed under 1-sun AM0 spectrum. 
Figure 1. Degradation in a) $\mathrm{J}_{\mathrm{sc}}$, b) $\mathrm{V}_{\mathrm{oc}}$, c) FF and d) $\mathrm{P}_{\max }$ of $\mathrm{Ge}$, GaAs and GaInP/Ge solar cells for in situ measurements at different $D_{d}$ of $10 \mathrm{MeV}$ proton irradiation. Two different devices are shown for each solar cell. An experimental uncertainty of $2 \%$ can be expected. Solid lines correspond to the data fitting of Eq. 1.

Figure 2. Dark I-V curves for BOL and EOL for GaInP/Ge, GaAs and Ge solar cells.

Figure. 3. (a) External Quantum Efficiency measurements and corresponding data fitting of the GaAs solar cell before (BOL) and after (EOL) $10 \mathrm{MeV}$ proton irradiation. (b) Calculated photogeneration rate (PGR) of the GaAs solar cell structure. BSF PGR is augmented by a factor of $10^{6}$. No ARC has been deposited.

Figure. 4. Dark I-V curves of representative GaAs solar cells at BOL and EOL and their corresponding data fitting. Black lines show the slopes of typical ideality factors of the two diode model.

Figure. 5. Normalized a) $\mathrm{J}_{\mathrm{sc}}$, b) $\mathrm{V}_{\mathrm{oc}}$, c) FF and d) maximum power output of two lattice-matched triple-junction GaInP/GaAs/Ge solar cells as a function of the $D_{d}$. The corresponding data fitting to Eq. 1 is shown in solid red lines while the fitting parameters are shown in the inset table.

Figure 6. External Quantum Efficiency at BOL and EOL of each subcell of a representative lattice matched triple-junction solar cell GaInP/GaAs/Ge. Dashed blue line shows the EQE of the Ge-subcell after correction. Black and red dashed lines correspond to the EQE measured in the single junction GaAs solar cell. No ARC has been deposited onto the solar cell.

Figure 7. Light I-V curve measured under 1-sun AM0 spectrum of a representative triple junction solar cell at BOL and EOL and their corresponding solar cell parameters. No ARC has been deposited onto the solar cell. 
a)

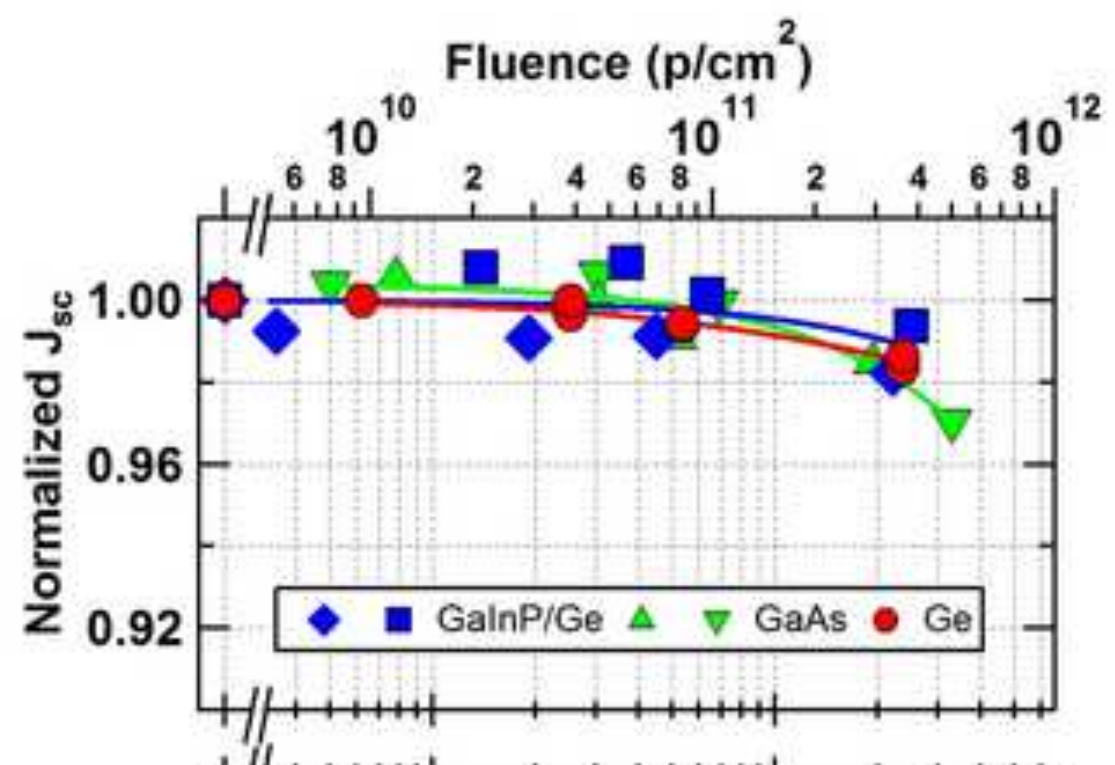

b)

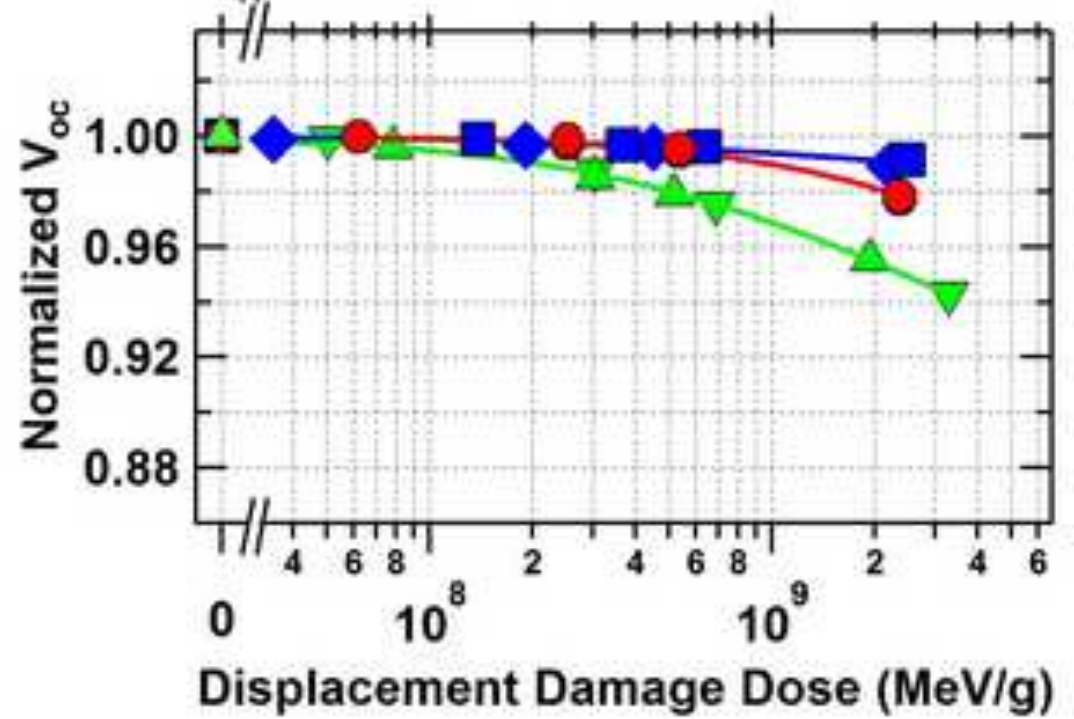

c)

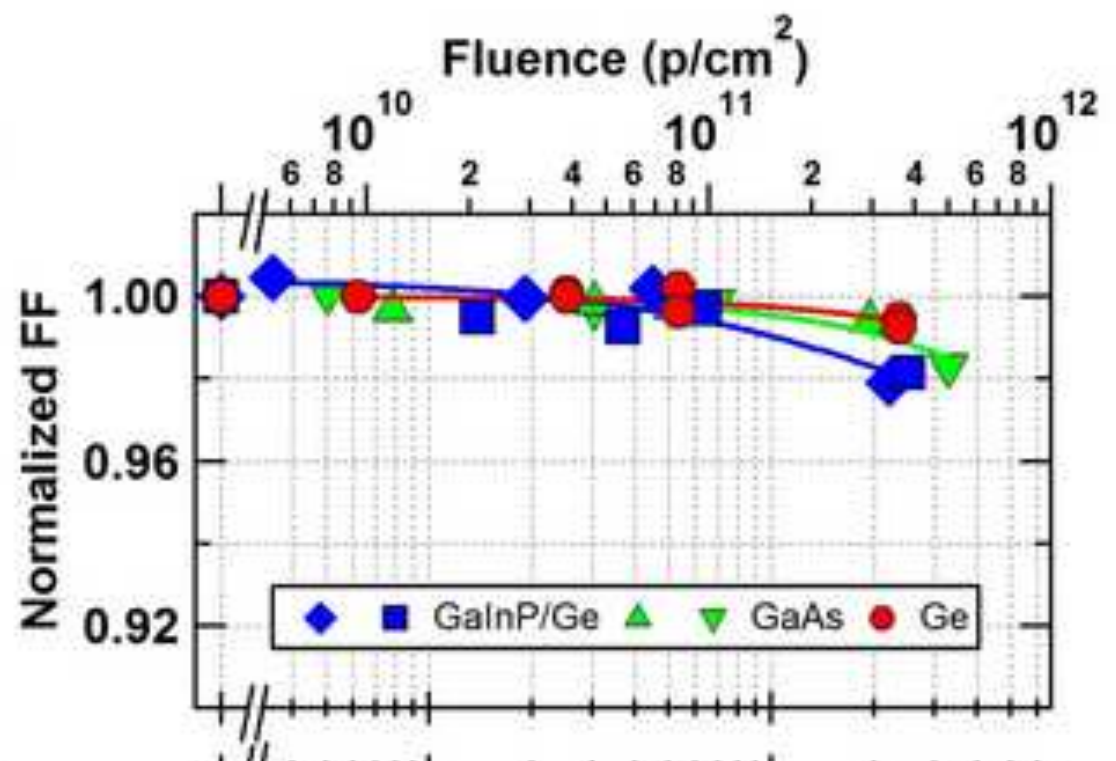

d)

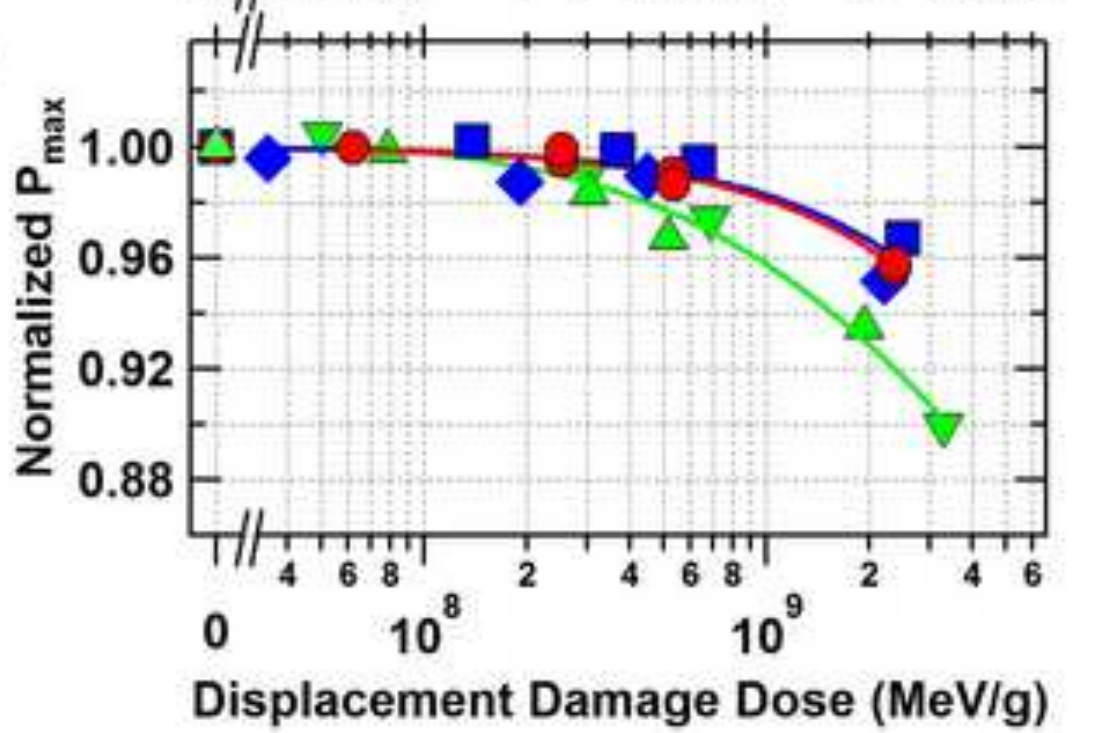




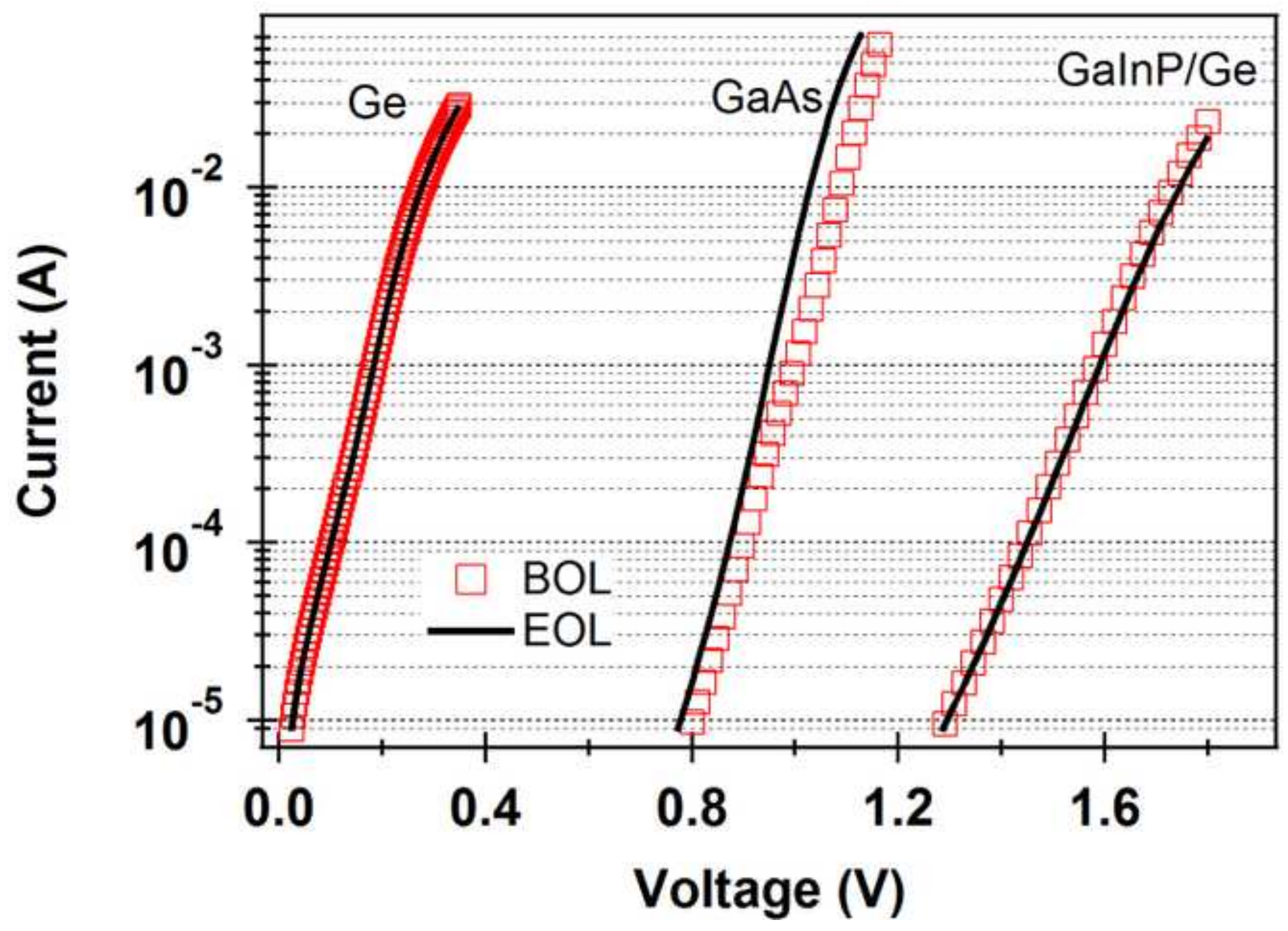




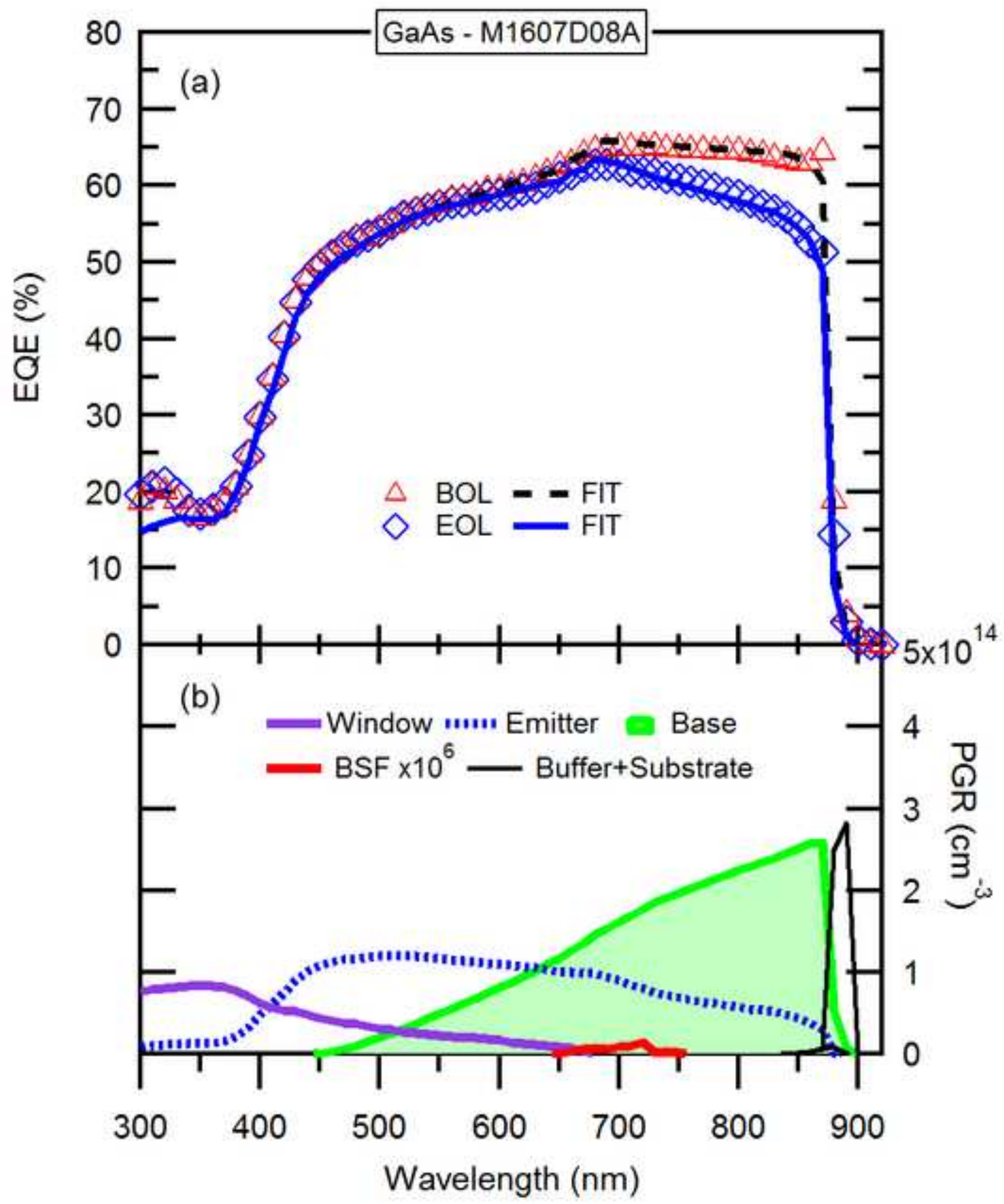




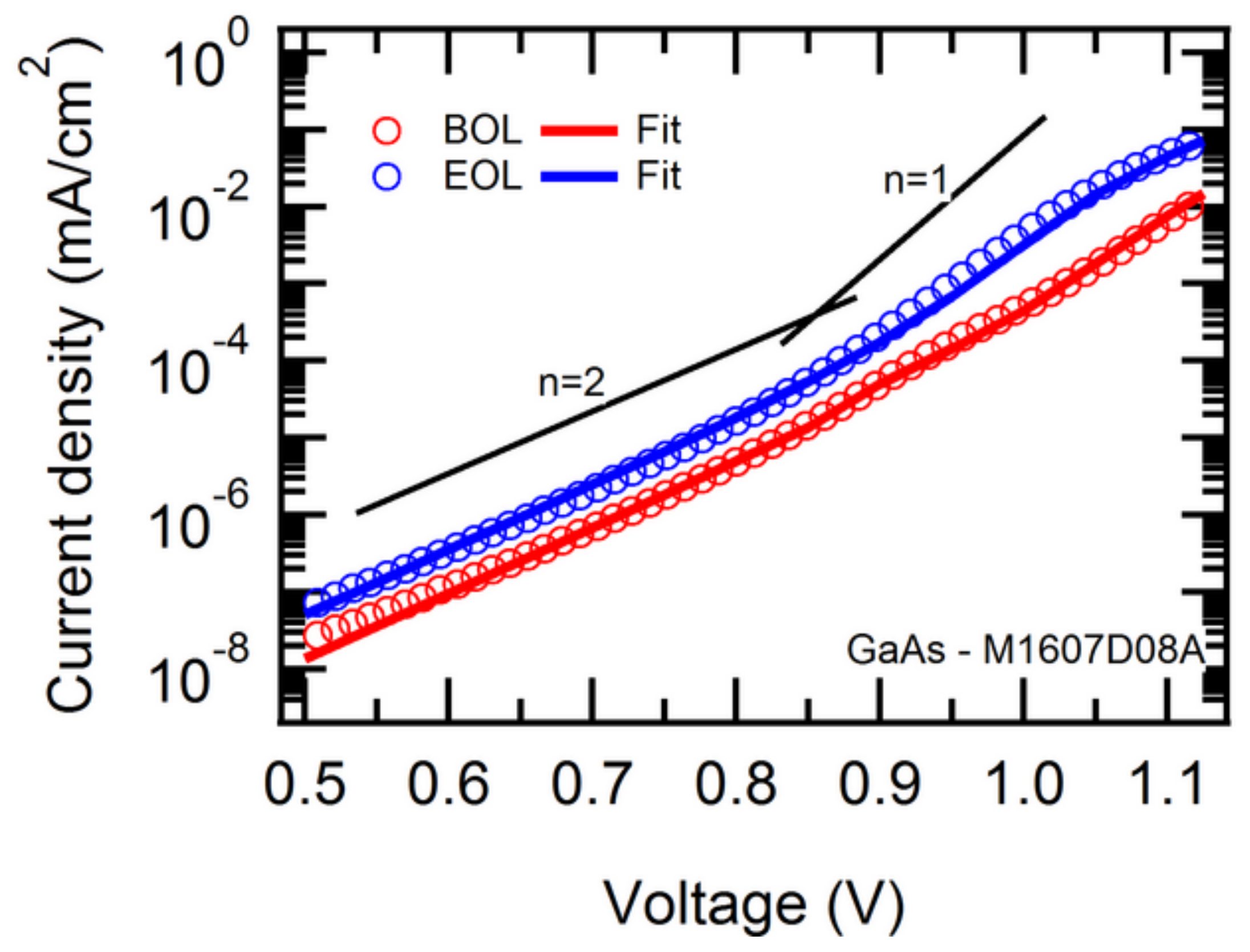



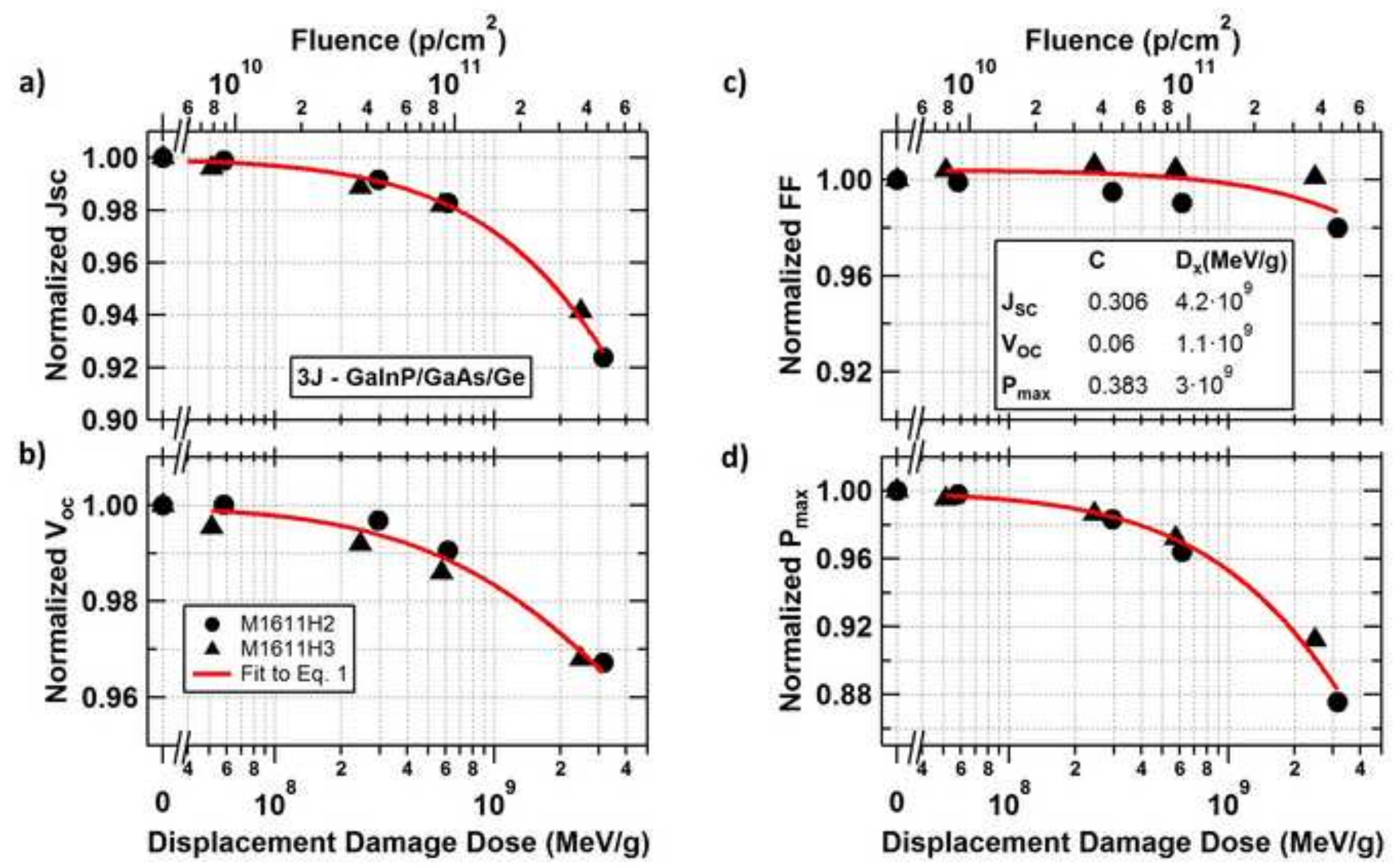

d)

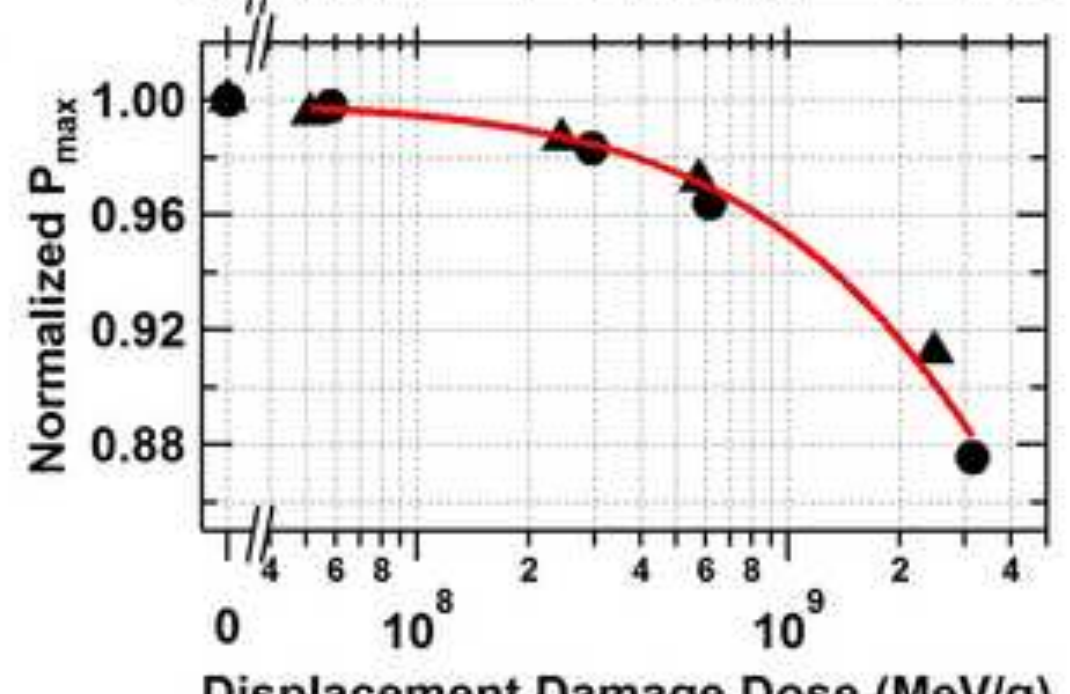

Displacement Damage Dose (MeV/g) 


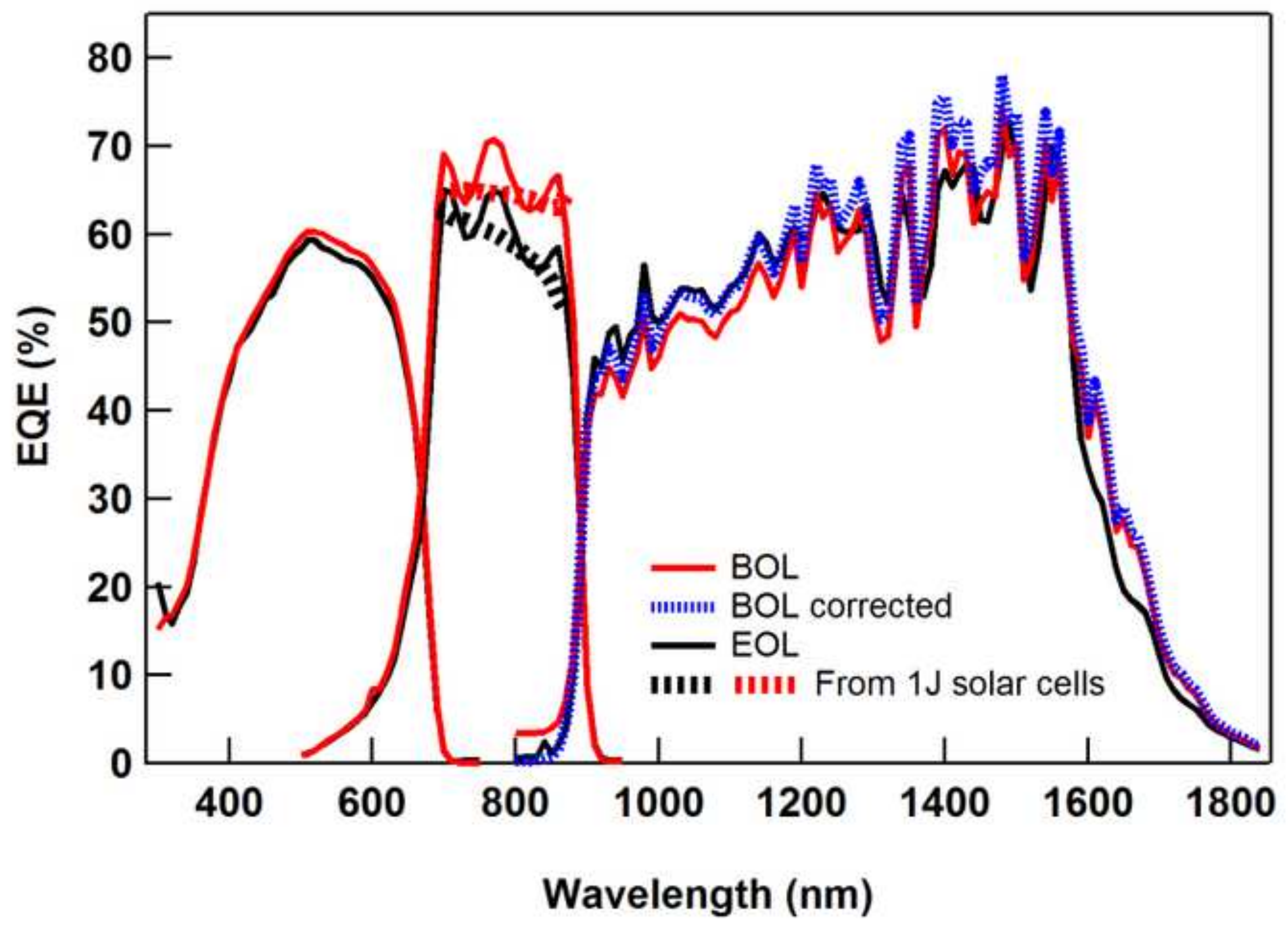




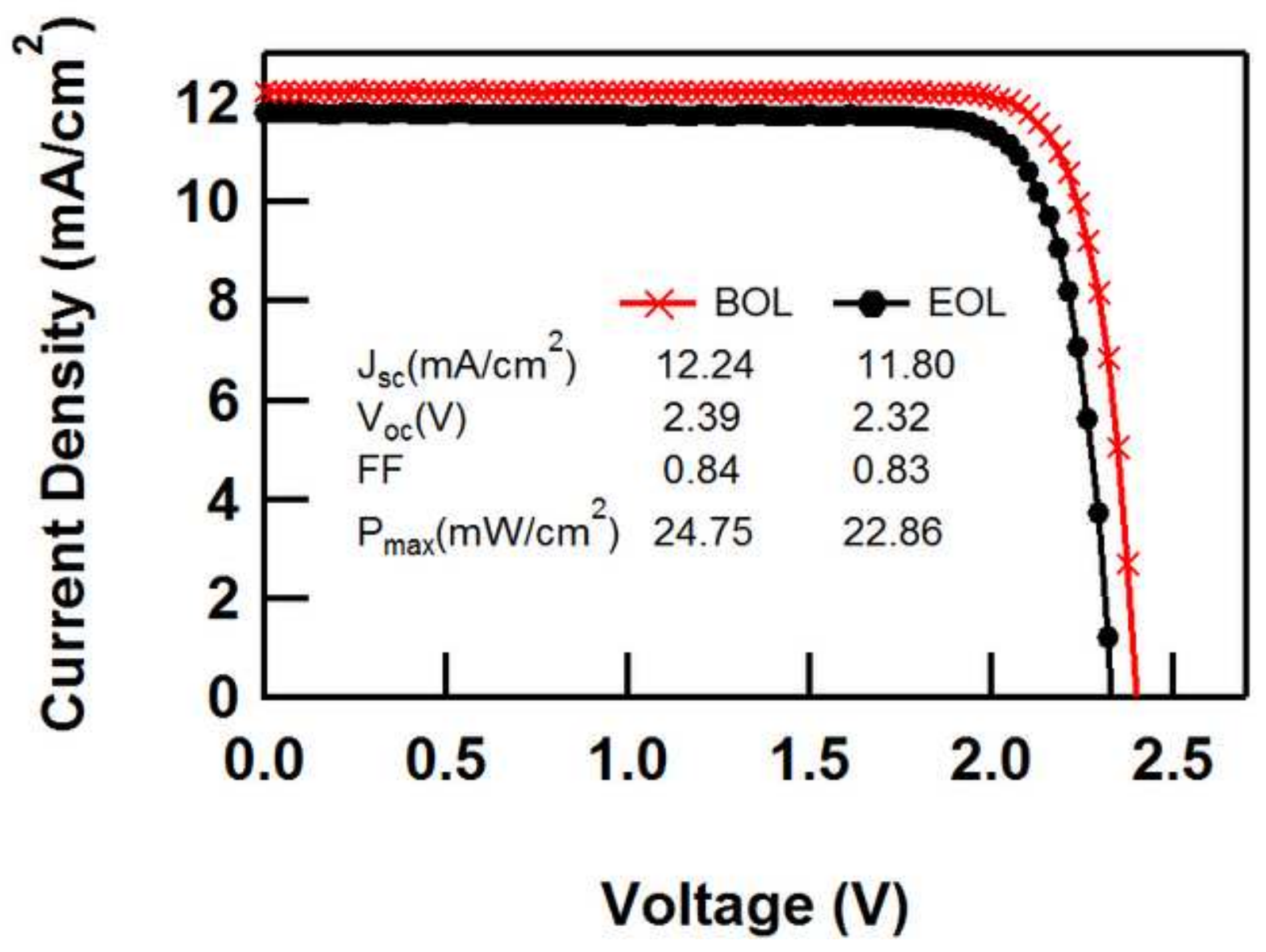

